\title{
K-ras gene mutation in gall bladder carcinomas and dysplasia
}

\author{
T Ajiki, T Fujimori, H Onoyama, M Yamamoto, S Kitazawa, S Maeda, Y Saitoh
}

\begin{abstract}
Epithelial dysplasia of gall bladder is an important precancerous lesion of gall bladder carcinogenesis. To investigate the frequency of $\mathrm{K}$-ras gene mutation in gall bladder carcinoma and dysplasia, K-ras codon 12 mutations were investigated by the polymerase chain reaction/restriction enzyme based method following direct sequencing. Mutation was detected in 59\% (30 of 51) of gall bladder carcinomas, in $73 \%$ (8 of 11) of gall bladder dysplasia in gall stone cases, and in $0 \%$ of the normal gall bladder epithelium. There was, however, no correlation between $\mathbf{K}$-ras mutation and clinicopathological factors of gall bladder carcinoma. K-ras gene mutation occurs even in gall bladder dysplasia at an incidence similar to that in carcinomas, suggesting that testing for $\mathbf{K}$-ras gene mutation may prove useful as an adjunct to bile cytological or biopsy analysis.

(Gut 1996; 38: 426-429)
\end{abstract}

Keywords: gall bladder carcinoma, dysplasia, K-ras, gall stone.

Previous investigations have show that K-ras activation may be important in the neoplastic process. ${ }^{1}$ The development of pancreatic and colonic cancer is associated with a high frequency of K-ras oncogene activation, which has been recognised as an early event in their carcinogenesis. ${ }^{2} 3$ In contrast, several reports have stated that $\mathrm{K}$-ras mutation is a later occurrence during tumour progression of myeloid leukaemia $^{4}$ and pancreatic cancer. ${ }^{5}$ Furthermore, at least some ras mutations have been reported to occur at various points during the evolution of tumours. ${ }^{4}$ In biliary tract carcinomas, a low frequency of K-ras mutations had been noted; recently, however, by using a sensitive detection method a higher frequency has been reported. ${ }^{6-8}$ These differences seem to result from the varying sensitivities of the methods used in the detection of such mutations.

Adenoma $^{9}$ and epithelial dysplasia ${ }^{10}$ have been recognised as precancerous lesions in the gall bladder tumour. Two studies have reported the occurrence of K-ras codon 12 mutation in gall bladder adenoma, supporting the adenoma-carcinoma theory of gall bladder carcinoma. ${ }^{67}$ While adenoma of the gall bladder is very rare and dysplasia is believed to be a significant precancerous lesion for gall bladder carcinomas, there is no report dealing with K-ras mutation of this lesion.

In this study, we have examined K-ras mutation in gall bladder carcinoma and dysplasia by using the highly sensitive polymerase chain reaction (PCR)/restriction enzyme based method, and have also investigated the relation between $\mathrm{K}$-ras mutation and clincopathological factors to elucidate the significance of K-ras mutation in the evolution of gall bladder tumours.

\section{Methods}

Fifty one gall bladder carcinomas, 11 epithelial dysplasias of the gall bladder, seven intrahepatic, and 10 extrahepatic bile duct carcinomas obtained at surgery or necropsy at Kobe University Hospital or its affiliates were analysed. Eleven $(10 \cdot 2 \%)$ epithelial dysplasias were selected from 108 gall stone cases by whole mapping of the gall bladders. Dysplastic lesions concurrent with nine carcinoma cases were also examined. Resected specimens were fixed with formalin and embedded in paraffin wax. Serial sections $5 \mu \mathrm{m}$ in thickness were stained with haematoxylin and eosin and examined microscopically. Histopathological diagnoses were assigned according to the AFIP classification. ${ }^{11}$ Dysplasia was neoplastic lesion and characterised by the loss of uniform alignment and the elongated hyperchromatic nuclei of cells (Fig 1), as reported by Dowling et al. ${ }^{10}$ The SW480 cultured colon carcinoma cell line that contains K-ras mutation at codon 12 was
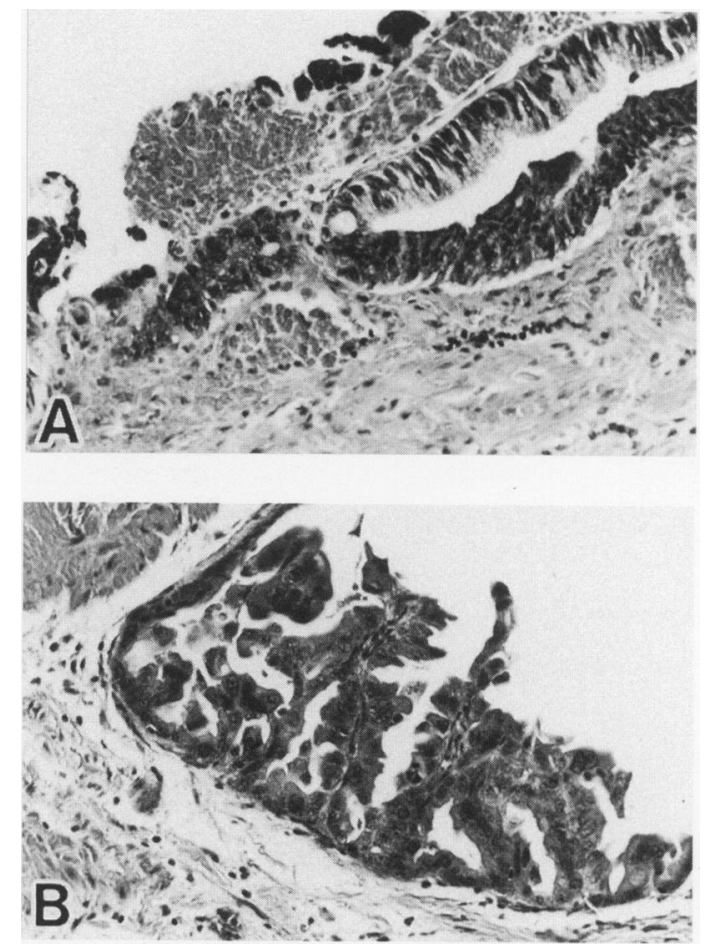

Figure 1: Example of dysplasia $(A)$ and carcinoma $(B)$ of the gall bladder. The atypical epithelium in dysplasia shows hyperchromatism and pseudostratification $(\times 200)$.
Correspondence to: Department of Pathology, Kobe University School of cho, Chuo-ku, Kobe, Hyogo Accepted for publication 7 September 1995 


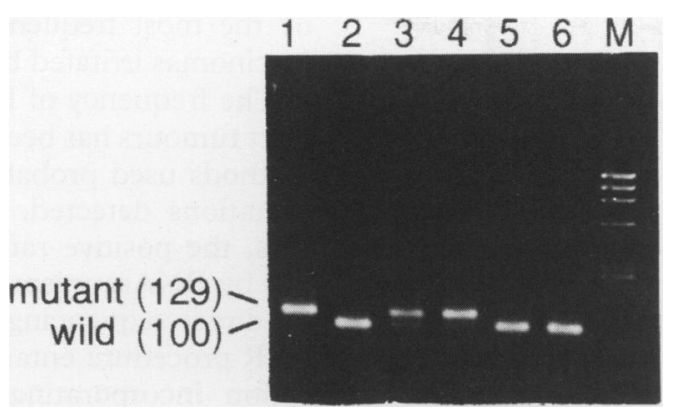

Figure 2: Detection of K-ras mutation by the two step PCR method. The upper band, $143 \mathrm{bp}$, indicates a mutant band and the lower, $114 \mathrm{bp}$, indicates a wild type band. Lane 1: SW 480 as positive control; lane 2: placental DNA as negative control; lanes 3-5: gall bladder dysplasia in gall stone cases; lane 6: normal gall bladder epithelium; M: $\Phi X$ 174-Hae III, DNA marker.

used as positive control ${ }^{12}$; placental DNA and DNA extracted from 10 normal gall bladder epithelium were used as negative control.

The hypercellular limited central parts of the tumour were microscopically cut out from 10 $\mu \mathrm{m}$ adjacent sections for DNA extraction. The sections were deparaffinised with xylene, cleared with ethanol, digested with proteinase $\mathrm{K}(1 \mathrm{mg} / \mathrm{ml})$, and boiled before the PCR procedure.

DNA was amplified as described by Watanabe et al $^{7}$ with slight modifications. One hundred $\mu l$ of the reaction mixture contained 1 $\mu \mathrm{g}$ of genomic DNA in $10 \mathrm{mM}$ TRIS (pH8.3), $50 \mathrm{mM} \mathrm{KCl}, 2.5 \mathrm{mM} \mathrm{MgCl}, 50 \mathrm{pmol}$ of each primer, $200 \mu \mathrm{M}$ deoxyribonucleoside triphosphates, and 2.5 units of Taq polymerase (Toyobo, Osaka, Japan). The samples were amplified in the first PCR for 35 cycles for one minute at $94^{\circ} \mathrm{C}$, two minutes of $55^{\circ} \mathrm{C}$, and one minute at $72^{\circ} \mathrm{C}$ followed by Mva I (Takara Shuzo, Kyoto, Japan) digestion, and in the second PCR of 25 cycles for one minute at $94^{\circ} \mathrm{C}$, two minutes of $59^{\circ} \mathrm{C}$, and one minute at $72^{\circ} \mathrm{C}$. The olignonucleotide primers used for the amplification were as follows: A (forward) 5'-ACTGAATATAAACTTGTGGTAGTTGGACCT-3', B (Reverse) 5'-TCAAAGAATGGTCCTGGACC-3', C (reverse) 5'-GCATATTAAAACAAGATTTAC-3'.

The underlined base represents a mismatch from the K-ras DNA sequence, which produces an Mva I (Takara, Shuzo, Kyoto, Japan) recognition site when codon 12 is normal. Primers were synthesised using a DNA synthesiser (Applied Biosystems, model 380A, Tokyo, Japan). The first PCR with primers $A$ and $B$ gave rise to a 157 base pair (bp) fragment containing Mva I restriction sites when codon 12 was normal. Twenty $\mu l$ of the product was digested with 10 units of Mva

TABLE I Frequency of $K$-ras mutation in biliary tract carcinomas

\begin{tabular}{llr}
\hline Tumour site & Positive/samples tested & $\%$ \\
\hline Gall bladder & & \\
carcinoma & $30 / 51$ & 59 \\
dysplasia & $8 / 11$ & 73 \\
normal epithelium & $0 / 10$ & 0 \\
Extrahepatic bile duct carcinoma & $5 / 10$ & 50 \\
Intrahepatic bile duct carcinoma & $5 / 7$ & 71 \\
\hline
\end{tabular}

I and electrophoresed on a 3\% agarose gel. Digested DNA was diluted with $\mathrm{H}_{2} \mathrm{O}$ (1:100), and one $\mu l$ of the sample was amplified in the second PCR with primers $A$ and $C$, generating a 129 bp fragment also containing Mva I restriction site when codon 12 was normal. Twenty $\mu l$ of the second PCR product was also digested with 10 units of Mva I and electrophoresed on a 3\% agarose gel.

The mutation bands detected by the above assay were purified using EASYTRAP (Takara, Kyoto, Japan) and confirmed by direct sequencing done by the dideoxy procedure using the DNA Sequencing System (Promega, Madison, WI, USA). In accordance with the manufacturer's instructions, $10 \mathrm{ng}$ of the template DNA were mixed with 3 pmol of the $C$ primer, 5 units of Taq polymerase, and $0.5 \mu \mathrm{l}$ of $\alpha-{ }^{32} \mathrm{P}-\mathrm{dCTP}$ in $16 \mu \mathrm{l}$ of buffer (250 $\mathrm{mM}$ TRIS- $\mathrm{HCl}$ and $10 \mathrm{mM} \mathrm{MgCl}_{2}$ ). Thirty cycles of amplification were carried out in a thermal cycler (ASTEC, Japan), each cycle comprising of 60 seconds at $94^{\circ} \mathrm{C}, 90$ seconds at $42^{\circ} \mathrm{C}$, and 60 seconds at $72^{\circ} \mathrm{C}$. PCR reaction were electrophoresed on $7 \%$ polyacrylamide-7 $M$ urea gels. Gels were dried and exposed to $x$ ray film for 12 hours.

The $\chi^{2}$ test was used for K-ras mutations and clinicopathological factors of tumours; $p$ values less than $5 \%$ were judged as statistically significant.

\section{Results}

Figure 2 shows representative analysis of the two step PCR/restriction enzyme based method for $\mathrm{K}$-ras codon 12 . Table I summarises the frequency of K-ras mutation as codon 12 in biliary tract tumours. The positive rate in gall bladder dysplasia or intrahepatic bile duct carcinoma was higher than that in extrahepatic bile duct carcinoma or gall bladder carcinoma, but these did not reach statistical differentiation. No mutation was detected in normal gall bladder epithelium.

Nine cases in our study exhibited dysplastic lesion in the area surrounding the carcinoma. These cases displayed the same K-ras mutation both in dysplastic and in carcinomatous lesions.

Table II summarises K-ras mutations and histopathological factors in gall bladder tumours. The frequency of $\mathrm{K}$-ras mutations in gall bladder carcinomas in situ (Tis) was lower than those in epithelial dysplasia and in advanced gall bladder carcinomas, but did not reach statistical significance. There was no correlation between $\mathrm{K}$-ras mutation and the distribution of dysplasia or histological subtype. The frequency of K-ras mutation in gall bladder carcinoma patients with stones was relatively higher than that in those without stones $(p=0 \cdot 157)$. K-ras mutation in dysplasia in gall stone cases was a $G$ to $T$ transversion (GGT $\rightarrow$ GTT) in four cases and a $G$ to $A$ transition (GGT $\rightarrow$ ACT) in four cases (Fig 3).

\section{Discussion}

Our results have confirmed that ras activation is already associated with the preinvasive event 


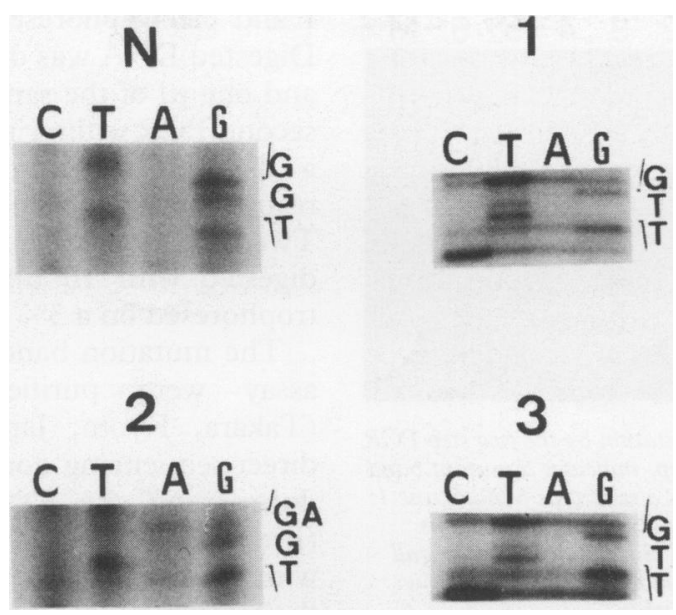

Figure 3: Examples of sequence determination of the K-ras codon 12 by direct sequencing. $N$ : normal gall bladder epithelium; 1: SW 480; 2,3: gall bladder dysplasia in gall stone cases.

of gall bladder tumorigenesis. The intestinal metaplasia - dysplasia - carcinoma sequence has been considered the main route of carcinogenesis in the gall bladder. ${ }^{13}$ In our study, point mutation of $\mathrm{K}$-ras was detected in epithelial dysplasia in gall stone cases with an incidence up to $73 \%$, which is similar to that in advanced carcinomas. Furthermore, carcinomatous and dysplastic portions in carcinoma cases also displayed the same K-ras mutations. Moreover, K-ras mutations did not correlate with clinicopathological factors in gall bladder carcinomas.

K-ras gene mutations have supported the hypothesis that most colon carcinomas arise through adenomas. ${ }^{2}$ In stomach cancer also, K-ras mutation have been detected only in differentiated but not in diffuse type carcinomas. ${ }^{14}$ In gall bladder carcinogenesis, Imai et $\mathrm{al}^{6}$ reported that three of five adenomas contained K-ras codon 12 mutations. Watanabe et $a l^{7}$ also reported that both the adenoma and carcinoma portions in the same tumour showed the same mutation, supporting the adenoma-carcinoma theory of gall bladder carcinoma. There are, however, few cases of adenoma in the gall bladder, ${ }^{9}$ and we did not detect any adenomas in the 108 mapped gall bladders. Moreover, as the positive rate of $\mathrm{K}$-ras mutation in differentiated type gall bladder carcinoma was similar to that in the undifferentiated type shows that adenomacarcinoma sequence may not cover most gall bladder carcinogenesis.

In our study, $G$ to $A$ transition at the first nucleotide of codon 12 and $G$ to $T$ transversion at the second nucleotide of codon 12 were detected in dysplasia from gall stone cases. Watanabe $e t$ al ${ }^{7}$ reported that GGT to GAT substitution is the most frequent K-ras mutation in gall bladder carcinoma. On the other hand, Imai et $a l^{6}$ reported that GGT to AGT substitution is the most frequent mutation $(69 \%)$ in gall bladder carcinoma. As previous investigators ${ }^{615}$ have pointed out, environmental factors may change mutation type. Moreover, we investigated mutation patterns of dysplasia detected from gall bladder stone cases, and GGT to AGT or GTT may possibly be the most frequent pattern in gall bladder carcinomas irritated by stone stimulation.

The frequency of K-ras mutations in biliary tract tumours has been variously reported. The methods used probably affect the numbers of mutations detected. In gall bladder carcinomas, the positive rate of K-ras mutation was $0 \%$ by RNAse mismatch cleavage assay ${ }^{16}$ and by direct sequencing, ${ }^{17} 55 \%$ by the sensitive PCR procedure entailing two steps of amplification incorporating nucleotide substitution within one PCR primer and endonuclease digestion with the specific restriction enzyme, ${ }^{7}$ and $39.9 \%$ by guanine-cytidine-clamped denaturing gradient gel electrophoresis. ${ }^{6}$ Our data $(59 \%)$ of gall bladder carcinoma were similar to those of Watanabe et $\mathrm{al}^{7}$ probably because of the same method of detection. Our incidence of K-ras mutation was higher in intrahepatic bile duct carcinoma than in extrahepatic bile duct or gall bladder carcinoma, but differences were not statistically significant. Although a different pathogenesis may be related to the tumour site from the viewpoint of K-ras mutation, ${ }^{717}$ more detailed studies are required to elucidate carcinogenesis in the biliary tract.

Several authors have reported that not all malignant cells in biliary tract tumours contain a mutation that occurs after clonal expansion of tumour cells. ${ }^{68}$ In other malignancies, only a fraction of tumour cells have shown K-ras gene mutation, for example acute lymphocyte leukaemia ${ }^{4}$ and pancreatic carcinoma. ${ }^{5}$ On the other hand, a carcinoma generally has monoclonal characteristics, and the stability of the $\mathrm{K}$-ras mutation throughout the natural history of human cancer is an established concept as represented by colon cancer. ${ }^{18}$ In this study, we did not detect mutations in many cases where we did not use the highly sensitive enriched PCR /restriction enzyme based method. These data agree with the existence of a heterogeneous population in biliary tract tumours as previously reported. From another point of view, these findings may be interpreted as being due to special characteristics or the environmental specificity of gall bladder carcinoma. Firstly, gall bladder carcinoma often occurs at multicentric points unlike pan-

TABLE II Different associations of K-ras mutation in gall bladder tumours

\begin{tabular}{lcc}
\hline Association & Positive/samples tested & $\%$ \\
\hline $\begin{array}{l}\text { Dysplasia } \\
\text { focal } \\
\text { diffuse }\end{array}$ & $5 / 7$ & \\
Staging & $3 / 4$ & 71 \\
Tis & $4 / 10$ & 75 \\
T1 & $2 / 4$ & 40 \\
T2 & $14 / 20$ & 50 \\
T3, T4 & $10 / 17$ & 70 \\
Histological type & $5 / 8$ & 59 \\
pap & $15 / 28$ & 63 \\
well & $8 / 12$ & 54 \\
poor & $2 / 3$ & 75 \\
others & $21 / 32$ & 67 \\
Stone & $9 / 19$ & 66 \\
present & & 47 \\
absent & & \\
\hline
\end{tabular}

pap = papillary adenocarcinoma; well $=$ well differentiated adenocarcinoma; poor=poorly differentiated adenocarcinoma; adenocarcinoma; poor $=$ poorly differentiated adenocarcinom
others included two adenosquamous carcinomas and one signet ring cell carcinoma. *Only carcinoma cases analysed. 
creatic or colonic carcinomas. ${ }^{19}$ Secondly, the chronic inflammatory change caused by stone retention or longtime bile exposure may correlate with the ras gene change. In fact, it is generally accepted that physical stimulation by stones is related to carcinogenesis in the gall bladder. ${ }^{20}$ In our study K-ras mutation was more frequently detected in gall bladder carcinomas with stones than in those without stones. Further, as bile salts act as a detergent in removing components from the plasma membrane, ${ }^{21}$ and as the bile components in carcinoma cases are different from benign cases, ${ }^{22}$ there may be a continuous initiation of $\mathrm{K}$-ras activation in carcinoma cases.

The two step PCR method is non-radioactive and highly sensitive in detecting a small population of mutated alleles, ${ }^{23}$ and its sensitivity is reported to be one in $512 .{ }^{8}$ The possibility of a sequencing error due to the Taq polymerase base misincorporation, however, has to be ruled out. In our study, normal gall bladder epithelium was always used as a negative control and the mutations following the direct sequencing method were confirmed. Chen et al reported that the Taq polymerase induced mutations were multiple base transitions. ${ }^{24}$

In conclusion, we have shown that carcinomas and epithelial dysplasia of gall bladder contain K-ras gene mutation. Thus the detection of K-ras gene mutation may prove useful as an adjunct to bile cytological or biopsy analysis and make possible the selection of patients for surgical resection. Further investigation is indicated for other genetic abnormalities because carcinogenesis implies a number of genetic changes involving oncogenes and tumour suppressor genes.

We thank Mr S Matsuda, Miss M Nishi, and Miss A Atsumi for technical assistance.

1 Fearon ER. K-ras gene mutation as a pathogenic and diagnostic marker in human cancer. $\mathcal{F}$ Natl Cancer Inst 1993, 85: $978-80$.

2 Vogelstein B, Fearon ER, Hamilton SR, Kern SE, Preisinger AC, Leppert $M$, et al. Genetic alterations during colorectal-tumour development. $N$ Engl $\mathcal{f} \mathrm{Med}$ 1988; 319: 525-32.

3 Cerny WL, Mangold KA, Scarpelli DG. K-ras mutations is an early event in pancreatic duct carcinogenesis in the syrian golden hamster. Cancer Res 1992; 52: 4507-13.

4 Kubo K, Naoe T, Kiyoi H, Fukutani H, Kato Y, Oguri T, et al. Clonal analysis of multiple point mutations in the
$\mathrm{N}$-ras gene in patients with acute myeloid leukemia. $\mathfrak{f p}_{p} \mathfrak{I}$ Cancer Res 1993; 84: 379-87.

5 Mariyama M, Kishi K, Nakamura K, Obata H, Nishimura $S$. Frequency and types of point mutations at the 12th codon of the c-Ki-ras gene found in pancreatic cancers from Japanese patients. Ipn $\mathcal{F}$ Cancer Res 1989; 80: 622-6.

6 Imai M, Hoshi T, Ogawa K. K-ras codon 12 mutations in biliary tract tumors detected by polymerase chain reaction denaturing gradient gel electrophoresis. Cancer 1994; 73: 2727-33.

7 Watanabe M, Asaka M, Tanaka J, Kurosawa M, Kasai M, Miyazaki T. Point mutation of K-ras gene codon in biliary tract tumors. Gastroenterology 1994; 107: 1147-53.

8 Levi S, Urbano-Ispizua A, Gill R, Thomas DM, Gilbertson $\mathrm{J}$, Foster C, et al. Multiple K-ras codon 12 mutations in cholangiocarcinomas demonstrated with a sensitive polymerase chain reaction technique. Cancer Res 1991; 51: 3497-502.

9 Kozuka S, Tsubone M, Yasui A, Hachisuka K. Relation of adenoma to carcinoma in the gallbladder. Cancer 1982 50: 2226-34.

10 Dowling GP, Kelly JK. The histogenesis of adenocarcinoma of the gallbladder. Cancer 1986; 58: 1702-8.

11 Albores-Saavedra J, Henson DE. Tumors of the gallbladder and extrahepatic bile ducts. In: Hartmann WH and Sobin and extrahe LH eds. Atlas of tumour pathology. 2nd series. Washington:

The Armed Forces Institute of Pathology, 1984; 28-123. Boom JH, van der Eb AJ, Bos JL. A dot-blot screeening procedure for mutated ras oncogenes using synthetic oligodeoxynucletoides. Gene 1986; 50: 313-20.

13 Yamagiwa H, Tomiyama H. Intestinal mataplasia - dysplasia - carcinoma sequence of the gallbladder. Acta Pathol fpn 1986; 36: 989-97.

14 Kihana T, Tsuda H, Hirota T, Shimosato Y, Sakamoto H, Terada $\mathrm{M}$, et al. Point mutation of c-Ki-ras oncogene in gastric adenoma and adenocarcinoma with tubular differentiation. Fpn f Cancer Res 1991; 82: 308-14.

15 Scarpa A, Capelli $P$, Villanueva A, Zamboni G, Lluis $F$ Accolla $R$, et al. Pancreatic cancer in Europe: Ki-ras gene Accolla $R$, et al. Pancreatic cancer in Europe: Ki-ras gene
mutation pattern shows geographical differences. Int $\mathcal{F}$ mutation pattern shows

16 Almoguera C, Shibata D, Forrester K, Martin J, Arnheim $\mathrm{N}$, Perucho M. Most human carcinomas of the exocrine pancreas contain mutant c-K-ras genes. Cell 1988; 53: 549-54.

17 Tada $M$, Omata $M$, Ohto $M$. Analysis of ras gene mutations in human hepatic malignant tumors by polymerase chain reaction and direct sequencing. Cancer Res 1990; 50: $1121-4$.

18 Losi L, Benhattar J, Costa J. Stability of K-ras mutations throughout the natural history of human colorectal cancer. Eur f Cancer 1992; 28A: 1115-20.

19Yamaguchi K, Enjoji M. Carcinoma of the gallbladder: a clinciopathology of 103 patients and a newly proposed clinciopathology of 103 patients and

20 Kimura W, Shimada H, Kuroda A, Morioka Y. Carcinoma of the gallbladder and extrahepatic bile duct in autopsy cases of the aged, with special reference to its relationship to gallstones. Am $\mathcal{F}$ Gastroenterol 1989; 84: 386-90.

21 Sagawa H, Tazuma S, Kajiwara G. Protection against hydrophobic bile salt-induced cell membrane damage by liposomes and hydrophilic bile salts. Am $\mathcal{F}$ Physiol 1993; 264: G835-9.

22 Takabayashi A, Watkins JB, Soloway RD, Rios-Dalenz J, Henson DE. Glycolithocolic acid is greatly increased in stones from patients with carcinoma of the gallbladder. Gastroenterology 1980; 79: 1058.

23 Kahn SM, Jiang W, Culbertson TA, Weinstein IB, Williams GM, Tomita N, et al. Rapid and sensitive nonradioactive GM, Tomita N, et al. Rapid and sensitive nonradioactive
detection of mutant K-ras genes via 'enriched' PCR detection of mutant K-ras genes via 'e

24 Chen J, Viola MV. A method to detect ras point mutations is small subpopulations of cells. Anal Biochem 1991; 195 $51-6$ 